\title{
Bilateral Symptomatic Discoid Medial Meniscus of the Knee: A Case Report and Review of Literature
}

\author{
Sunil Gurpur Kini ${ }^{1,2,}$; Peter Walker ${ }^{1}$; Warwick Bruce ${ }^{1}$ \\ ${ }_{1}^{1}$ Department of Orthopedics, Concord Repatriation General Hospital, Sydney, Australia \\ ${ }^{2}$ Department of Orthopedics, University College London Hospitals (UCLH), London, United Kingdom \\ ${ }^{*}$ Corresponding author: Sunil Gurpur Kini, Department of Orthopaedics, University College London Hospitals, London, United Kingdom. Tel:+44-2034475042, Fax: +44-2034479958, \\ E-mail:drsunilkini@gmail.com \\ Received: January 8, 2015; Accepted: February 16, 2015
}

\begin{abstract}
Introduction: A discoid medial meniscus is a rare pathology of the knee joint, and is even rarer when it presents bilaterally with clinical symptoms.

Case Presentation: We present the case of a 38-year-old female with symptomatic bilateral discoid medial meniscus. Magnetic Resonance Imaging (MRI) showed complete discoid meniscus in one knee and incomplete, on the other side. The MRI findings were confirmed on arthroscopy, with horizontal cleavage tear in both knees. Arthroscopic partial meniscectomies of both menisci were performed.

Conclusions: The patient had an excellent functional outcome at the most recent follow-up, with no recurrence of symptoms and full range of movements.

Keywords: Magnetic Resonance Imaging; Arthroscopy; Medial Menisci
\end{abstract}

\section{Introduction}

The first case of medial discoid meniscus was reported by Watson Jones (1) in 1930 and subsequently, by Cave and Staples, in 1941 (2). The prevalence of medial discoid menisci is extremely rare, with an incidence of $0.06 \%$ $0.3 \%$ compared to that observed for lateral discoid menisci (1.4\%-15.5\%). A retrospective study, including 14731 menisci, assessed bilateral cases, which were even more rare (0.012\%) (3). Symptoms of locking and giving away in both knees were the main symptoms. The Magnetic Resonance Imaging (MRI) confirmed the presence of bilateral discoid menisci with tears and the symptoms resolved promptly with arthroscopic partial meniscectomies.

\section{Case Presentation}

A 38-year-old female presented to us with medial knee pain in both her knees. Pain initially started in one knee, 3 years back, followed by the involvement of the other knee, 3 months back. There was no history of trauma. The patient complained of intermittent locking and giving away symptoms. Examination revealed medial joint line tenderness and positive McMurray's sign, with normal range of movements. Radiographs were inconclusive and MRI findings were suggestive of bilateral discoid medial menisci, with horizontal cleavage tears (Figure 1 and 2). No anomalies of the anterior horn of the medial menisci were noted.

The patient was taken up for surgery, in view of her symptoms. Arthroscopy revealed bilateral discoid medial menisci, the complete type, in one knee, and incomplete type, in the other. Horizontal cleavage tears were found in both knees. Partial medial meniscectomies were performed bilaterally, with resection of the central portion of the discoid meniscus. Physiotherapy was commenced immediately postoperatively, with isometric exercises and weight bearing, as tolerated. The patient was symptom free at a 12-month follow-up. Examination revealed no joint line tenderness, with negative McMurray testing and full range of movements.

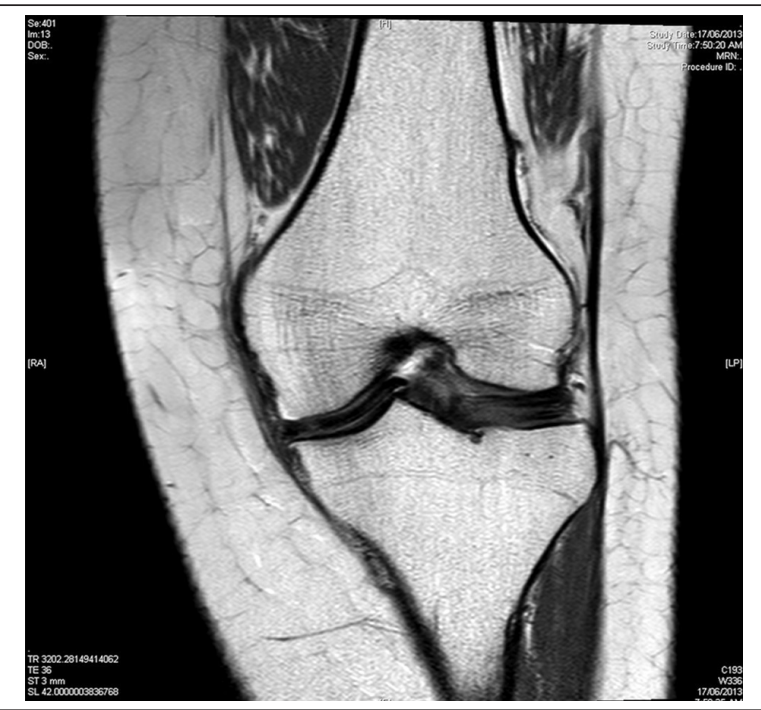

Figure 1. Magnetic Resonance Imaging Coronal Section Showing the Discoid Meniscus

Copyright ( () 2015, Kashan University of Medical Sciences. This is an open-access article distributed under the terms of the Creative Commons Attribution-NonCommercial 4.0 International License (http://creativecommons.org/licenses/by-nc/4.0/) which permits copy and redistribute the material just in noncommercial usages, provided the original work is properly cited. 


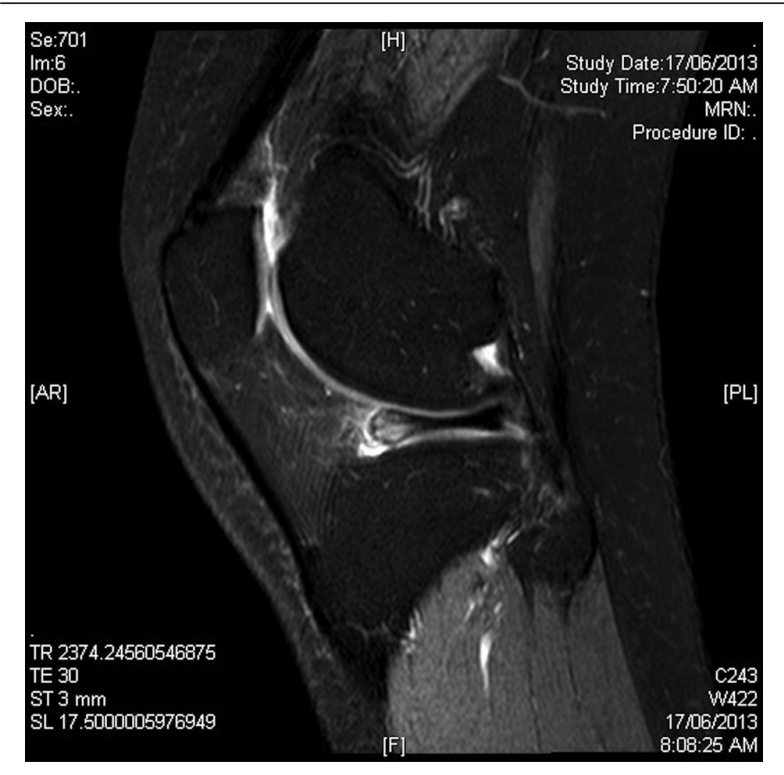

Figure 2. Magnetic Resonance Imaging Sagittal Section Showing Discoid Meniscus

\section{Discussion}

Discoid medial meniscus is a rare abnormality, with an estimated incidence of $0.12 \%$. Cases with bilateral involvement are even more rare (1). The etiopathogenesis of discoid meniscus is still unclear. Smillie postulated that it was the persistence of the fetal cartilaginous disc in adulthood that leads to discoid meniscus (4). Kaplan has stated that it is acquired due to changes in the attachment of the posterior coronary ligament by the meniscofemoral ligament of Humphry, which becomes hypermobile (5). Discoid meniscus were classified according to the degree of tibial plateau cover and presence/absence of posterior attachment, which resulted in a three type classification (complete, incomplete and Wrisberg variant). The Wrisberg variant includes menisci that are hypermobile and lack posterior coronary ligament and capsular attachments. Associated anomalies with discoid medial menisci include depression of the tibial plateau, anomalous attachment of the anterior horn to the Anterior Cruciate Ligament (ACL), meniscal cyst, pathologic medial patella plica, and discoid lateral meniscus, on the same knee (6-10).

Pinar et al. (6) reported two cases of bilateral medial discoid menisci. One of them had severe radiographic changes in the form of cupping of the medial tibial plateau and lytic lesion of the distal medial femoral condyle. Both cases were symptomatic in only one knee, which was operated at the moment. They concluded that the short-term results of arthroscopic meniscectomy may not be as satisfactory as those reported for normal menisci. Lee et al. (8) reported symptomatic bilateral discoid meniscus with abnormal attachment to the ACL, in three patients. The patients had symptoms bilaterally, and five knees were operated upon.
Flouzat-Lachaniette et al. (11) reported four cases of medial discoid menisci, with one bilateral involvement. Meniscal tears were seen in all the cases, of which two were horizontal and two were vertical. Three cases showed abnormal insertion of the anterior horn of the medial meniscus into the ACL. All cases were treated by meniscoplasty, with associated meniscal repair in one case. Cho (12) reported one case of bilateral discoid menisci with unilateral symptoms. The patient was treated with saucerization and arthroscopic all-inside meniscal repair. Common symptoms of a symptomatic discoid medial meniscus are pain in the knee, intermittent edema, locking of the knee, sensations of giving way and clicking of the knee and extensor lag. Radiographs, in selected cases, may show a widened medial joint space with squaring of the femoral condyles (13) or depression of the tibial plateau (6).

The MRI is usually diagnostic, showing discoid medial meniscus with associated tears and anomalies of attachment of the meniscal horns. The diagnosis requires continuity between the anterior and posterior horns on three consecutive $5 \mathrm{~mm}$ sagittal slices (14) and is confirmed by coronal slices, showing an abnormally thick meniscus, sometimes extending as far as the intercondylar notch (14-16). On multiple occasions, the discoid meniscus is largely asymptomatic and only a small number of authors, like Tachibana and Lee, have recommended performing MRI studies of the other knee in a unilateral presentation, so as to not miss the diagnosis $(8,14)$. The treatment of symptomatic discoid medial meniscus is essentially surgical. Arthroscopy identifies the type of discoid meniscus and associated tears/unstable flaps. Partial meniscectomy, with excision of the central anomalous discoid meniscus and preservation of stable peripheral rim, is the preferred treatment. Several tears are amenable to arthroscopic repair. The patients must always be counseled that they are always at a higher risk for meniscal injuries in the future due to the abnormal morphology of the meniscus and hence, might require lifestyle and activity modification.

Bilateral medial discoid menisci represent an extremely rare presentation. The most common presentation is medial joint line tenderness, with catching or locking episodes. The MRI is the investigation of choice that also helps delineate associated meniscal tears and anomalies of the attachments of the meniscal horns. Arthroscopic partial meniscectomy/meniscoplasty is the treatment of choice in symptomatic patients. Although surgical outcomes are largely good, patients must be warned of an increased risk of meniscal injuries in the future due to abnormal meniscal morphology and hence, the need for activity modification, especially in the younger age group.

\section{Authors' contributions}

Sunil Gurpur Kini: preparation of the manuscript; Peter 
Walker: operated in the patient; Warwick Bruce: assisted on editing of the manuscript.

\section{References}

1. Jones RW. Specimen of Internal Semilunar Cartilage as a Complete Disc. Proc R Soc Med.1930;23(11):1588-9.

2. Cave EF, Staples OS . Congenital discoid meniscus of cause of internal derangement of the knee. Am J Surg. 1941;54(1):371-6.

3. Dickason JM, Del Pizzo W, Blazina ME, Fox JM, Friedman MJ, Snyder SJ. A series of ten discoid medial menisci. Clin Orthop Relat Res. 1982(168):75-9.

4. Smillie IS. The congenital discoid meniscus. J Bone Joint Surg Br. 1948;30B(4):671-82.

5. Kaplan EB. Discoid lateral meniscus of the knee joint; nature, mechanism, and operative treatment. J Bone Joint Surg Am. 1957;39-A(1):77-87.

6. Pinar H, Akseki D, Karaoglan O, Ozkan M, Uluc E. Bilateral discoid medial menisci. Arthroscopy. 2000;16(1):96-101.

7. Franceschi F, Longo UG, Ruzzini L, Simoni P, Zobel BB, Denaro V. Bilateral complete discoid medial meniscus combined with posterior cyst formation. Knee Surg Sports Traumatol Arthrosc. 2007;15(3):266-8.
8. Lee BI, Lee YS, Kwon SW, Choi SW, Cho KH, Kwon YJ. Bilateral symptomatic discoid medial meniscus: report of three cases. Knee Surg Sports Traumatol Arthrosc. 2007;15(6):739-43.

9. Min BH, Ha HK, Khang SY. Medial discoid meniscus completely coalesced with the anterior cruciate ligament. Arthroscopy. 2001;17(7):E27.

10. Cha JG, Min KD, Han JK, Hong HS, Park SJ, Park JS, et al. Anomalous insertion of the medial meniscus into the anterior cruciate ligament: the MR appearance. BrJ Radiol. 2008;81(961):20-4.

11. Flouzat-Lachaniette $\mathrm{CH}$, Pujol N, Boisrenoult P, Beaufils P. Discoid medial meniscus: report of four cases and literature review. Orthop Traumatol Surg Res. 2011;97(8):826-32.

12. Cho J. Bilateral complete discoid medial meniscus: a case report. J Knee Surg. 2011;24(1):67-70.

13. Lowenberg DW, Feldman ML. Magnetic resonance imaging diagnosis of discoid medial meniscus. Arthroscopy. 1993;9(6):704-6.

14. Tachibana Y, Yamazaki Y, Ninomiya S. Discoid medial meniscus. Arthroscopy. 2003;19(7):E12-8.

15. Blacksin MF, Greene B, Botelho G. Bilateral diskoid medial menisci diagnosed by magnetic resonance imaging: a case report. Clin Orthop Relat Res. 1992(285):214-6.

16. Silverman JM, Mink JH, Deutsch AL. Discoid menisci of the knee: MR imaging appearance. Radiology.1989;173(2):351-4. 